\title{
Adsorption, kinetics and thermodynamic studies of Lead (II) ions from aqueous solutions onto bio- adsorbent prepared from locust bean seed shell
}

\author{
Jeje, O. Ayorinde ${ }^{1^{*}}$, Oregbeme, Henry ${ }^{2}$ and Osula, J. E. ${ }^{1}$ \\ ${ }^{1}$ Department of Basic Sciences, Federal Polytechnic Auchi, Nigeria. \\ 2Department of Science Laboratory Technology, Federal Polytechnic Auchi, Nigeria. \\ *Corresponding author. Email: jaminjeje@gmail.com
}

Copyright (C) 2019 Jeje et al. This article remains permanently open access under the terms of the Creative Commons Attribution License 4.0, which permits unrestricted use, distribution, and reproduction in any medium, provided the original work is properly cited.

Received 22nd February, 2019; Accepted 29th April, 2019

\begin{abstract}
Adsorption has been widely used for the removal of heavy metals from waste water due to its availability, efficiency, profitability and its low cost of operation. In this study, locust bean seed shell powder prepared from locust been seed shell (LBSS) was used as adsorbent. Batch adsorption experiments were carried out in order to study the effect of process variables such as; adsorbent dosage, time, concentration, and temperature. The adsorbents both unmodified and modified were characterized using SEM, XRF, and FTIR. The results showed structural modification of the modified locust bean seed shell powder (MLBSSP). The adsorption equilibrium data of MLBSSP perfectly conform to Freundlich adsorption model based on its high correlation coefficient which is close to unity (0.9738). However, the kinetic studies showed that the process fit in well into pseudo second order due to its higher $\mathrm{R}^{2}(0.9662)$ in MLBSSP. The positive values obtained for change in enthalpy indicate that the adsorption process is endothermic in nature while the negative values obtained for change in entropy of the process reveal decrease in the randomness of the process and the positive values of change in Gibb's free energy suggest non spontaneity of the adsorption process. The adsorbent (MLBSSP) shows excellent performance in removing $\mathrm{Pb}$ (II) ions from aqueous solutions and can be used as a substitute to the available expensive adsorbents since it is cheap, non-toxic and abundantly available.
\end{abstract}

Keywords: Locust bean seed coat, adsorption, $\mathrm{Pb}$ (II) ions, kinetics, thermodynamics.

\section{INTRODUCTION}

There has been a worldwide public awareness for the heavy metal contamination and toxicity in aquatic environment. Many heavy metals like lead $(\mathrm{Pb})$, mercury $(\mathrm{Hg})$, cadmium $(\mathrm{Cd})$, arsenic $(\mathrm{As})$, chromium $(\mathrm{Cr})$, zinc $(\mathrm{Zn})$, and copper $(\mathrm{Cu})$, etc. have widespread usage in industries and enter the environment wherever they are produced, used, or discarded. All these metals become seriously toxic as ions or compound being soluble in water and readily absorbable by living organisms (Sharma et al., 2016). Nowadays, the natural water resources are being contaminated by different pollutants as a result of increase in population and industrialization (Ali et al., 2016). It is well known that management and quality of water are very important in human life. Growth of technologies and industrialization resulted to increase in percentage quantity and accumulation of waste all over the entire globe and its attendant release of heavy metals, phenols, and dyes into the water bodies (Hashem et al., 2017). Industrialization grows so rapidly that the discharge of heavy metals into the environment increases accordingly (Mondal et al., 2015).

Generally, metals and their derivatives are very harmful when they are released into the atmosphere and discharge into the environment and can be particularly problematic due to their stability and mobility (Gnanasundaram et al., 2017). These harmful heavy metals are output from varieties activities such as industrial, waste disposal, agricultural and others (Ariffin et al., 2017). The contamination of water by industrial activities constitutes serious challenges to human health and the environment 
(Hameed et al., 2007). Heavy metals are toxic and pose a threat to man and the environment (Zupanc et al., 2002). Accumulation of heavy metals in streams due to discharge of untreated or poorly treated waste water poses serious health challenge to human bodies and ultimately leads to death (Ariffin et al., 2017). Technologies employed in the treatment of waste water include chemical precipitation, ion-exchange, adsorption, membrane filtration, coagulation-flocculation, flotation and electrochemical (Ariffin et al., 2017). All these methods with exception of adsorption are not cost effective, have low output and inefficient in removing trace level of heavy metals from wastewater.

Adsorption remains the outstanding process due to its simplicity, high efficiency and easy recovery (Ndi Nsami et al., 2013). All heavy metals are toxic, non-biodegradable and as a result should be removed from waste water before discharging into the water bodies (Priyanka 2017). Adsorption process has been singled out to be a feasible substitute for removing heavy metals from waste water however; other natural and synthetic solids have been investigated as adsorbents of heavy metals removal from aqueous solutions. Among which include zeolite, clay, silica gel, resin, activated alumina and activated carbon (Ketchaq et al., 2007., Ketcha et al., 2012). Also, other bio-adsorbents that have been investigated include pillared clay (Vinod and Anirudhan, 2001), cassava waste (Abia et al., 2003), caladium bi colour (Horsfall and Spiff, 2004, Horsfall and Spiff, 2005), maize cob and husk (Igwe and Abia 2003). Activated carbon is the most widely used adsorbent as a result of its well-developed pore structure, large active surface area, excellent mechanical properties and multiple functional groups at their surface (Wu et al., 2005, Kouotou et al., 2013). Though efficient but the high cost of activated carbon limits its large scale use for heavy metals removal. Thus, the objective of this study was to investigate the potential of locust bean seed coat powder prepare from locust bean seed coat for the removal of lead ions from aqueous solutions.

\section{MATERIAL AND METHODS}

Locust bean seed pods was sourced locally from Auchi, Edo State, Nigeria. The seed coat was removed by cooking for 1 hour 30 minutes to soften the strongly attracted seed coat for easy dehulling. The resulting wet seed shells were transferred into a thermostatically controlled electric oven and dried at $105^{\circ} \mathrm{C}$ for 6 hours, allowed to cool and ground into powdery form with an electric blender. The locust bean seed shell powder (LBSSP) was sieved into different particle sizes using sieves of $300,250,200,150$, and 100 microns. The powdered sample (particle size of 100 microns) was stored in a dry air tight plastic container for further investigation and the adsorption process.

\section{Activation of the adsorbent}

The LBSSP was treated with $2 \mathrm{M} \mathrm{HCl}$ by adding $400 \mathrm{~mL}$ of the acid to $250 \mathrm{~g}$ of the sample and left to stand for 48 hours. The resulting mixture was stirred and washed severally with deionized water until the filtrate became neutral to litmus. The wet residue was analytically transferred into an electrostatically control oven and dried for 3 hours at $105^{\circ} \mathrm{C}$. The dried modified locust bean seed shell powder (MLBSSP) was kept in an air-tight container for further use as an adsorbent. This process could lead to the introduction of more functional groups on the surface of the powdered adsorbent (Drake et al., 1996, Parvathi et al., 2007, Okieimen and Okieimen, 2001).

\section{Characterization of adsorbents}

The adsorbents (modified and unmodified) were characterized using FTIR for surface functional group, XRD for the mineral composition, SEM for surface morphology.

\section{Preparation of solutions}

The reagents used in this study were of analytical grade. All lead (II) ions solutions were prepared using deionized water. A $1000 \mathrm{mg} / \mathrm{L} \mathrm{Pb}$ (II) ions stock solution was prepared by dissolving $\mathrm{Pb}\left(\mathrm{NO}_{3}\right)_{2}$ in deionized water. All working solutions were prepared by diluting the stock solutions with deionized water.

\section{Data analysis}

\section{Adsorption studies}

The adsorption experiment was conducted using the batch method to determine the effects of the different parameters on the sorption process. The adsorption experiments for the removal of lead ions were conducted by adding $2.0 \mathrm{~g}$ of unmodified locust bean seed shell powder (ULBSSP) with $50 \mathrm{~mL}$ of a solution of known concentration in $200 \mathrm{~mL}$ flasks at room temperature. The influence of initial lead ion concentration was performed in the range 2.0 to $4.0 \mathrm{mg} / \mathrm{L}$, time 15 to 35 minutes, adsorbent dosage 1.0 to $3.0 \mathrm{~g}$, and temperature 15 to $50^{\circ} \mathrm{C}$. In each case, the parameter studied was varied while others were kept constant. At the end of the stirring and agitation time required in each case, the solution was filtered and the filtrate was analyzed for residual lead (II) ions concentration using atomic absorption spectrophotometer (AAS). The data obtained in the batch studies was used to determine the amount of metal ions adsorbed at any time by the difference in their initial and final concentrations. Each experiment was 
carried out in duplicate. The same procedure was repeated for modified locust bean seed shell powder (MLBSSP). The adsorbent uptake capacity was calculated according to equation 1

$q_{e}=\frac{\left(C_{o}-C_{e}\right) V}{m}$

The percent removal of $\mathrm{Pb}$ (II) ions in solution was calculated using equation 2

$\%$ Removal Efficiency (RE) $=\frac{C_{o}-C_{e}}{C_{o}} \times 100$

\section{Isotherm studies}

The data obtained for lead (II) ions was fitted into linearized equations of Langmuir and Freundlich models. The Langmuir isotherm has been applied in various adsorption processes in the form of equation 3.

$$
\frac{\mathrm{Ce}}{\mathrm{x}}=\frac{1}{\mathrm{KLXm}}+\frac{\mathrm{Ce}}{\mathrm{Xm}}
$$

Where $\mathrm{x}=$ amount of solute adsorbed $(\mathrm{x} / \mathrm{m}), \mathrm{C}_{\mathrm{e}}=$ residual amount at equilibrium, $\mathrm{m}=$ grams of adsorbent used, $\mathrm{K} \mathrm{L}$ ( $\mathrm{K} \mathrm{L}$ is the Langmuir binding constant and related to the energy of adsorption) is the surface area of the adsorbent $\left(\mathrm{m}^{2} / 100 \mathrm{~g}\right)$, and $X_{m}$ a constant, is the intensity of the adsorption. The essential characteristics of the Langmuir isotherm can be expressed in terms of a dimensionless constant separation factor $R\llcorner$ and is calculated according to equation 4.

$R_{L}=1 /\left(1+K_{L} C_{0}\right)$

Where $\mathrm{C}_{\circ}$ is the initial concentration of $\mathrm{Pb}$ (II) ions in the solution $(\mathrm{mg} / \mathrm{L})$, the value of $R L$ indicates the nature of the isotherm to be either unfavourable $(R L>1)$, linear $(R L=1)$, favoureable $(0<R L<1)$ and irreversible $(R L=0)$.

Freundlich developed an empirical equation that correlates the capacity of the adsorbent with the residual solute concentration according to equation 5

$\frac{\mathrm{x}}{\mathrm{m}}=\mathrm{k} c^{n}$

The constant $n$ is sometimes expressed as $1 / n$ to standardize notation so that the constant varies only between 0.1 and 1.0 (Achife et al., 1989). Empirical data are evaluated for Freundlich behaviour by using the equation in its logarithmic form, as equation of a straight line, according to equation 6 (Achife et al., 1989).

$\log \frac{x}{m}=\log k+n \log c$

Where $\mathrm{x}=$ amount of solute adsorbed $(\mathrm{mg}), \mathrm{m}=$ amount of adsorbent $(\mathrm{g}), \quad \mathrm{c}=$ amount of residual solute (concentration) $(\mathrm{mg} / \mathrm{L})$ at equilibrium. $\mathrm{K}$ is a constant indicating adsorption capacity, and $\mathrm{n}$ is a constant which indicate the intensity of adsorption.

\section{Kinetic studies}

The prediction of adsorption kinetics is the most important factor as it describes the solute uptake rate which intern controls the residence time of solute uptake at the solid liquid interface (Pegnanelli et al., 2003, Mondal, 2009). In order to investigate the adsorption mechanism of lead (II) ions onto ULBSSP and MLBSSP, two kinetic models were tested, pseudo-first order.

$\log (q e-q t)=\log q e-\frac{K_{1}}{2.303}$

Where $q_{e}$ and $q_{t}$ refer to the amount of dye adsorbed $(\mathrm{mg} / \mathrm{g})$ at equilibrium and at any time $t(\mathrm{~min})$ respectively, and $\mathrm{K}_{1}$ is the equilibrium rate constant of Pseudo- first order adsorption. The slope and intercept of plot of log (qe qt) against $t$ were used to determine the Pseudo-first order rate constant $\mathrm{K}_{1}$ for the adsorption process. The pseudosecond-order models is represented by equation 8 .

$$
\frac{\mathrm{t}}{\mathrm{q}_{\mathrm{t}}}=\frac{1}{\mathrm{~K}^{2} \mathrm{q}_{\mathrm{e}}^{2}}+\frac{1}{\mathrm{q}_{\mathrm{e}}} \mathrm{t} .
$$

Where $\mathrm{K}_{2}(\mathrm{~g} / \mathrm{mg} \mathrm{min})$ is the equilibrium rate constant of pseudo second order adsorption.

The slope and intercept of plot of $\frac{t}{q_{t}}$ against $t$ were used to calculate the pseudo-second order parameters.

\section{Thermodynamic studies}

The effect of temperature on the lead ions adsorption onto the surface of both ULBSSP and MLBSSP at different temperatures $\left(15,20,30,40\right.$, and $\left.50^{\circ} \mathrm{C}\right)$ was investigated at $\mathrm{pH}$ of 5.0. Thermodynamic functions of adsorption process were calculated using thermodynamic equation 9.

$\ln X_{e}=\frac{\Delta S^{o}}{R}-\frac{\Delta H^{\circ}}{R}\left(\frac{1}{T}\right)$

The values of $\Delta H$ and $\Delta S$ can be obtained from the slope and intercept of the graph by plotting $\ln X_{\mathrm{e}}$ against $\frac{1}{\mathrm{~T}}$, while change in free energy is calculate using $\Delta G=\Delta H-\mathrm{T} \Delta S$.

\section{RESULTS AND DISCUSSION}

\section{Fourier Transforms Infrared Analysis (FT-IR)}

The analytical technique for the characterization of both modified and unmodified locus bean seed coat was achieved using FT-IR (Perkine-Elmer 1000 spectrophotometer) 


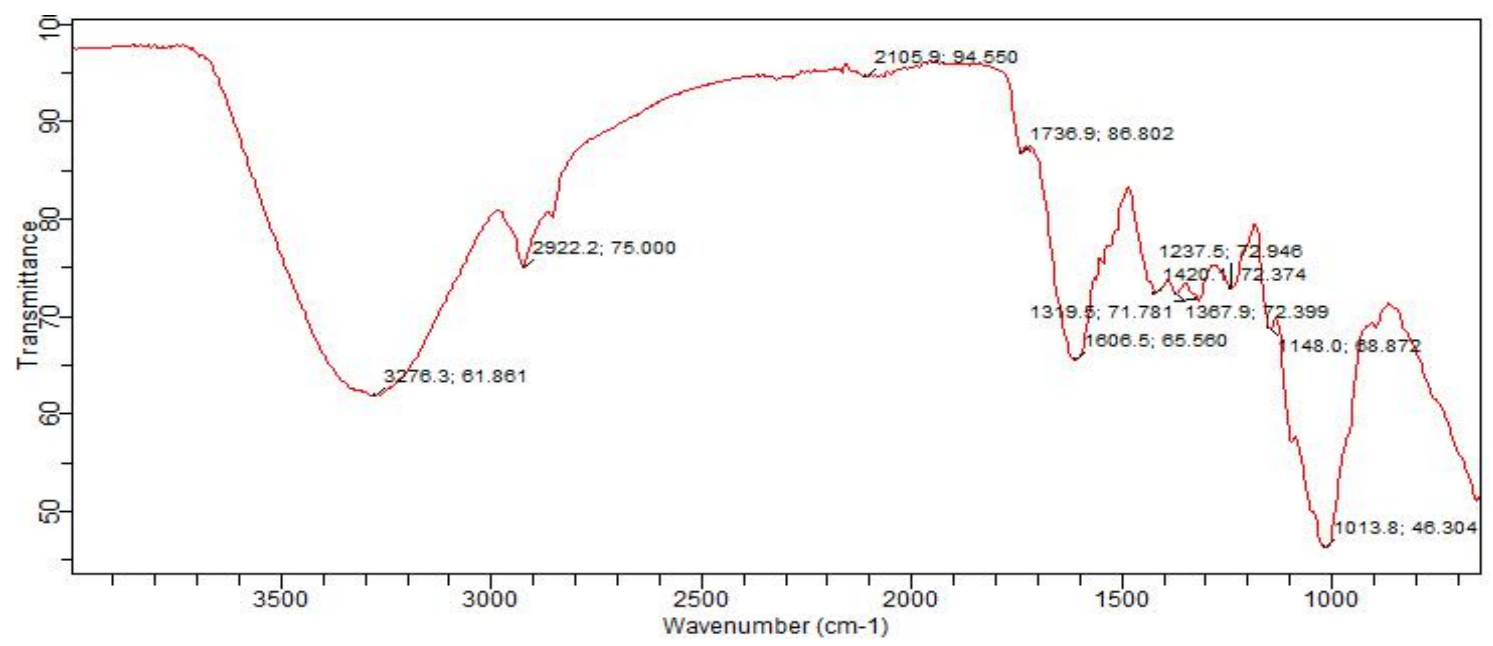

Figure 1. FTIR spectrum of ULBSC.

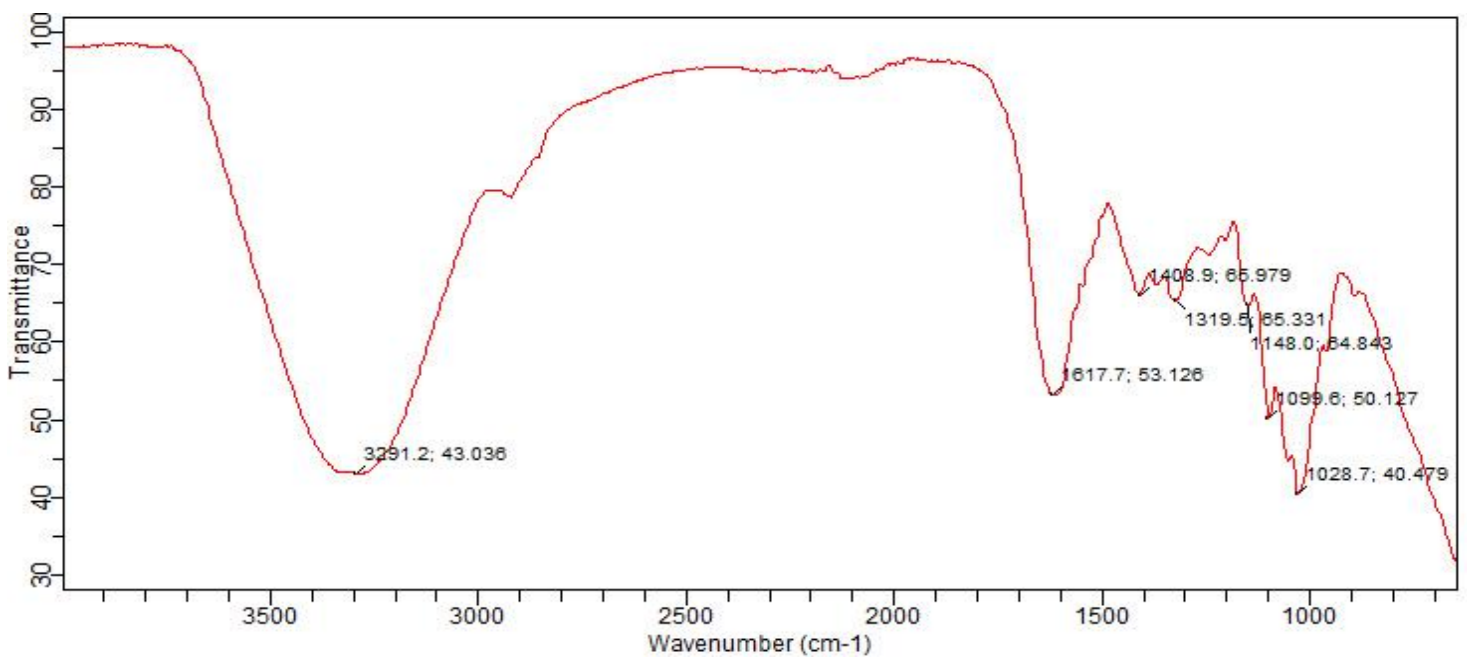

Figure 2. FT-IR spectrum of MLBSC.

spectroscopy. The quality features of infrared spectroscopy have been so useful and one of the most effective tools for characterization (Breen et al., 1995) especially for functional groups. For the elucidation of the interactions and structural modification of LBSSP were obtained over a range of 4000 to $650 \mathrm{~cm}^{-1}$.

Presented in Figures 1 and 2 are the spectra of unmodified locust bean seed shell powder (ULBSSP) and modified locust bean seed shell (MLBSSP). The results clearly revealed some modifications in the MLBSSP modified with $2 \mathrm{M} \mathrm{HCl}$. This was evident in shifting and disappearing of some absorption bands as compared with ULBSSP. For instance, the absence of absorption bands at $2922.2,2105.9,1738.9$, and $1237.5 \mathrm{~cm}^{-1}$ and shifting of band from $1013.8 \mathrm{~cm}^{-1}$ in ULSBSP to $1028.7 \mathrm{~cm}^{-1}$ in MLBSSP showed the effect of modification in the properties of the sample.
The absorption bands (strong intensity and very broad) at 3276.3 and $3291.2 \mathrm{~cm}^{-1}$ in both ULBSSP and MLBSSP samples were due to the presence of $\mathrm{O}-\mathrm{H}$ groups. The absorption peak at $2922.2 \mathrm{~cm}^{-1}$ in ULBSSP was as a result of $\mathrm{C}-\mathrm{H}$ stretch from alkane, while the weak intensity band at $2105.9 \mathrm{~cm}^{-1}$ was due to $\mathrm{C}=\mathrm{C}$ group. However, the absorption peaks at 1608.5 and $1738.9 \mathrm{~cm}^{-1}$ were due to $\mathrm{C}=\mathrm{O}$ from carboxylic group. The peaks at 1319.6 and $1367.9 \mathrm{~cm}^{-1}$ were $\mathrm{CH}_{2}$ scissoring probably from alkyl group. The absorption bands at 1237.5 and $1013.8 \mathrm{~cm}^{-1}$ were as a result of $\mathrm{C}-\mathrm{O}$ from carbonyl group while the band at $1148.0 \mathrm{~cm}^{-1}$ was due to O-C-O group. The MLBSSP also showed strong intensity and very broad absorption band at $3291.2 \mathrm{~cm}^{-1}$ and indication of the presence of $\mathrm{OH}$ stretching from carboxylic group. The absorption peaks at $1617.7,1148.0,1099.6$ and $1028.7 \mathrm{~cm}^{-1}$ were due to the presence of C-O probably from carboxylate group. 


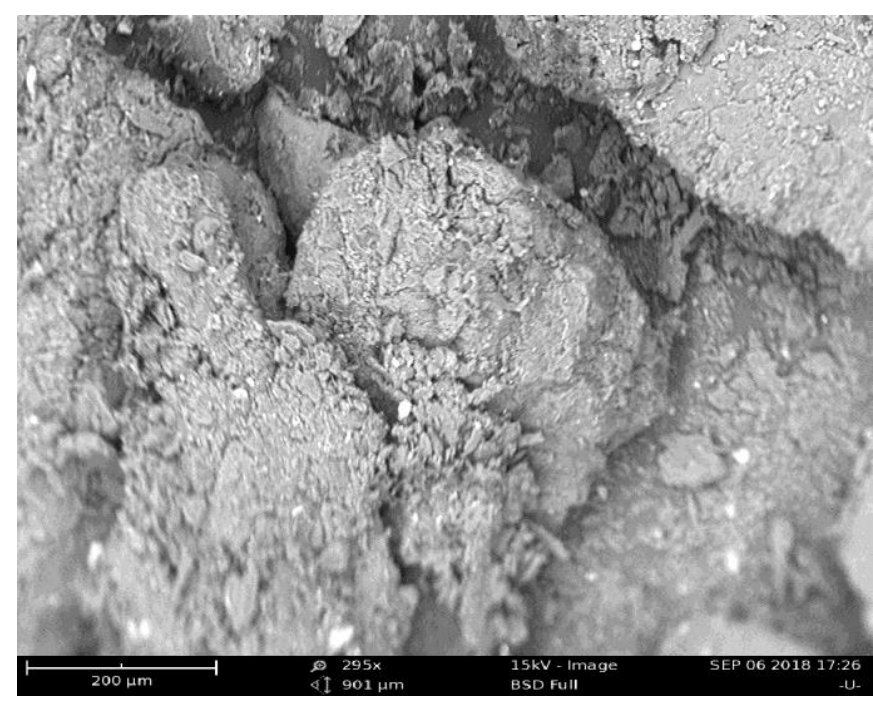

Figure 3. SEM Spectrum of ULBSC.

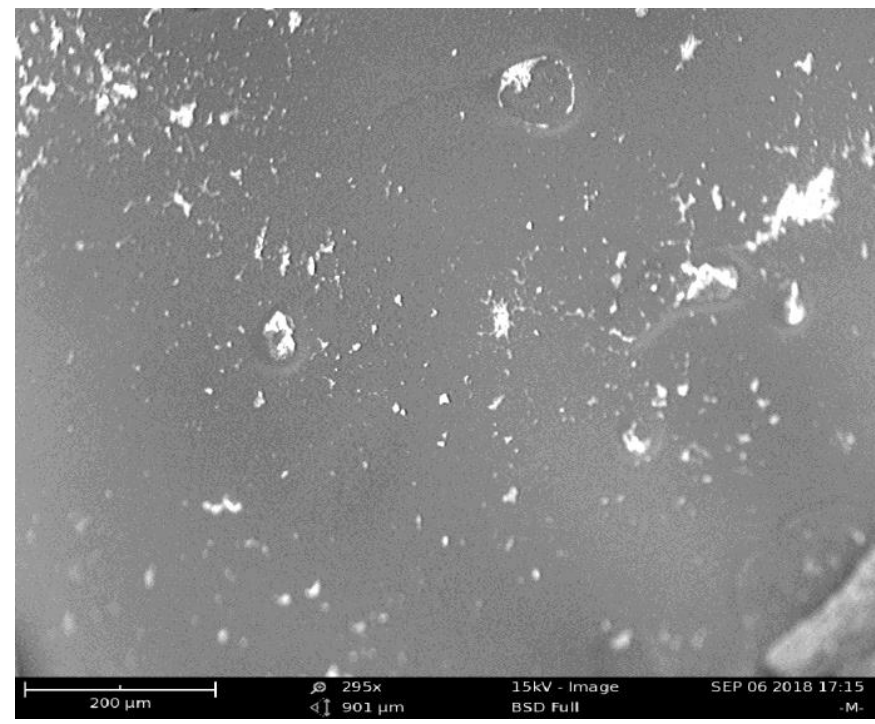

Figure 4. SEM Spectrum of MLBSC.

However, the appearance of peak at $1408.0 \mathrm{~cm}^{-1}$ showed the presence of $\mathrm{N}-\mathrm{H}$ bending and the band at $1319.6 \mathrm{~cm}^{-1}$ was due to $\mathrm{CH}_{2}$ scissoring. The absence of peaks in the spectra range of 900 to $650 \mathrm{~cm}^{-1}$ regions indicated the absence of aromatic ring.

\section{Scanning Electron Microscopy (SEM) Analysis (Phenom Prox by phenomworld Eindhoven Netherlands)}

Presented in Figures 3 and 4 are the scanning electron micrographs of ULBSSP and MLBSSP. The SEM
Table 1. Elemental composition of ULBSCP and MLBSCP.

\begin{tabular}{lcc}
\hline Compound & ULBSC $(\mathbf{W t} \%)$ & MLBSC $(\mathbf{W t} \%)$ \\
\hline $\mathrm{Na} 2 \mathrm{O}$ & 0.000 & 0.000 \\
$\mathrm{MgO}$ & 3.884 & 0.672 \\
$\mathrm{Al}_{2} \mathrm{O}_{3}$ & 5.221 & 5.682 \\
$\mathrm{SiO}_{2}$ & 26.634 & 2.938 \\
$\mathrm{P}_{2} \mathrm{O}_{2}$ & 4.416 & 2.254 \\
$\mathrm{SO}_{3}$ & 22.276 & 12.956 \\
$\mathrm{~K}_{2} \mathrm{O}$ & 15.440 & 3.242 \\
$\mathrm{CaO}$ & 16.760 & 6.873 \\
$\mathrm{TiO}_{2}$ & 0.721 & 0.570 \\
$\mathrm{Mn}_{2} \mathrm{O}_{3}$ & 0.654 & 0.287 \\
$\mathrm{Fe} \mathrm{O}_{3}$ & 1.818 & 1.274 \\
$\mathrm{ZnO}$ & 0.108 & 0.043 \\
$\mathrm{SrO}$ & 0.090 & 0.036 \\
\hline
\end{tabular}

micrographs were studied for the surface and morphological characteristics in the samples. The photographs show that the surface morphology of the ULBSSP appears in form of flake -like, shaft, rough, rigid and with tiny particles closely packed together, however, the MLBSSP sample appears to be more porous with gravity within the surface and this could be as a result of the treatment of the sample with $2 \mathrm{M} \mathrm{HCl}$ whereby some of the impurities and other minerals have been leached from the sample.

\section{Elemental composition of ULBSSP and MLBSSP}

X-ray fluorescence (XRF) analysis (Philip pW 1390) for the ULBSSP and MLBSSP were presented in Table 1. The results showed elemental composition of MLBSSP and ULBSSP powder were leached from the sample. This was evident in the overall reduction in the concentration of elements present after modification with the acid (2 M $\mathrm{HCl})$. However, the exception was observed in weight percentage of the oxide of aluminum with little increase in its weight percentages.

\section{Effects of adsorbent dosage}

Effects of adsorbent dosage in the removal of lead ions from aqueous solutions for ULBSSP and MLBSSP were varied from 1.0 to $3.0 \mathrm{~g}$ of $50 \mathrm{mg} / \mathrm{L}$ of aqueous solution containing the metal ions. The results revealed the percentage metal ions adsorbed by both the ULBSCP and MLBSSP as shown in Figure 5. It was observed that MLBSSP has the higher percentage removal from aqueous solutions using $1.0 \mathrm{~g}$ of MLBSSP. The amount adsorbed by MLBSSP decrease when 1.5 and $2.0 \mathrm{~g}$ of MLBSSP were used. However, while the percentage 


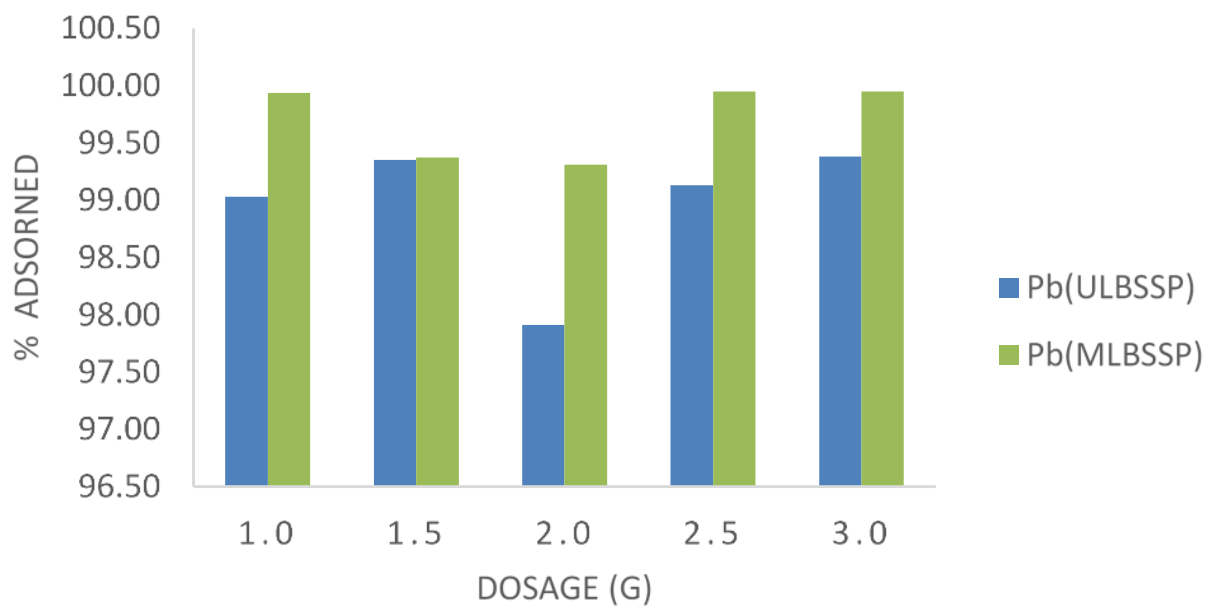

Figure 5. Effect of dosage on percent removal of $\mathrm{Pb}$ (II) ions.

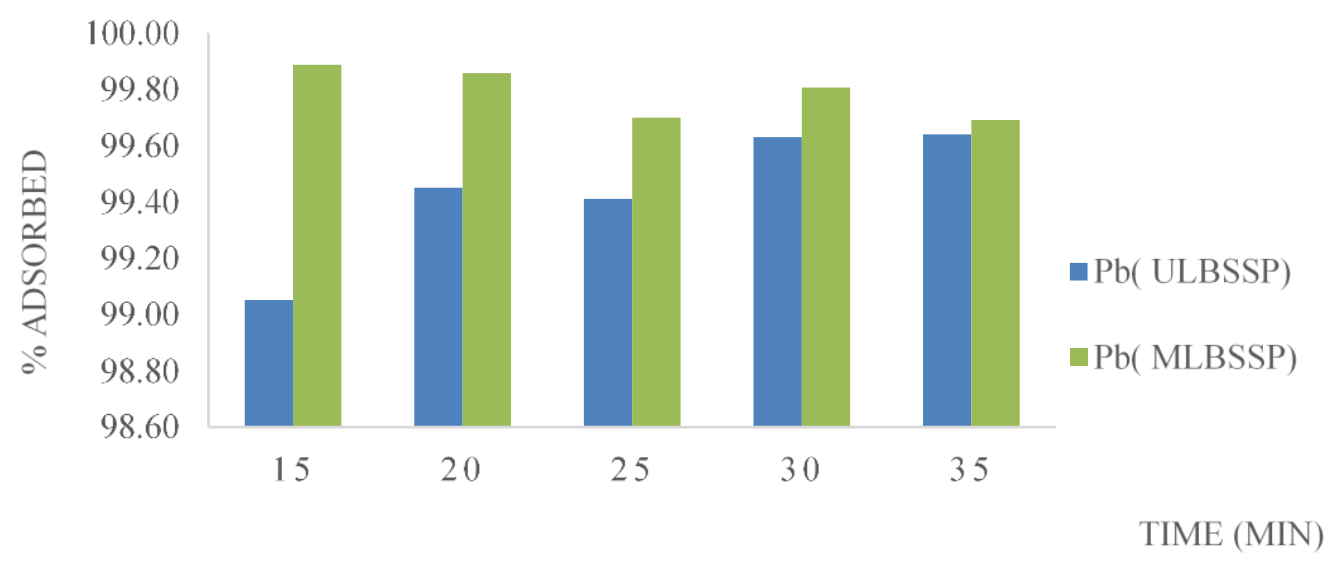

Figure 6. Effect of contact time on percent removal of $\mathrm{Pb}$ (II) ions.

removal efficiency increased at $2.5 \mathrm{~g}(99.95 \%)$ and remain constant when the dosage was increased to $3.0 \mathrm{~g}(99.95$ $\%$ ) indicating that adsorption equilibrium has been reached and no further removal of lead ions from aqueous solutions. As shown in Figure 5, a dose of $1.0 \mathrm{~g}$ is sufficient to remove more than $99 \%$ lead ions from $50 \mathrm{mg} / \mathrm{L}$ initial concentration of lead ions within 30 minutes since further increase of the adsorbent dosage to $2.0 \mathrm{~g}$ resulted in the decrease of percentage removal of lead ions from aqueous solutions. The decrease in percentage removal experience was due to the saturation of available adsorption active sites during the adsorption process. No significant increase was noticed when the adsorbent dosage was increased from 2.5 to $3.0 \mathrm{~g}$ which suggested that after a certain dosage of adsorbent, the maximum adsorption was attained and the quantity of ions bound to the adsorbent and the quantity of free ions remains constant even with further addition of adsorbent dosage. This is similar to studies reported by Abdel-Ghani et al. (2007), Teker et al. (1999) and Mittal (2006). The result shows that the MLBSSP performed better than ULBSSP in the adsorption of lead (II) ions from aqueous solutions.

\section{Effect of contact time}

The effect of contact time as it affected the degree of metal ions removal by both ULBSS and MLBSSP from aqueous solutions is presented in Figure 6 . The results showed the percentage removal efficiencies of the adsorbents. It was observed that the highest percentage removal of lead ions was noticed at 15 minutes contact time with 99.89 at 50 $\mathrm{mg} / \mathrm{L}$ and $2 \mathrm{~g}$ adsorbent.

Decrease in percentage removal of lead ions was observed at contact time of 20 and 25 minutes. This indicated that all the available adsorbent active sites have been occupied by lead (II) ions and no further adsorption of the ions could occur which led to the decrease in percentage removal of the ions however, an increase in percentage removal of lead ions was observed at contact 


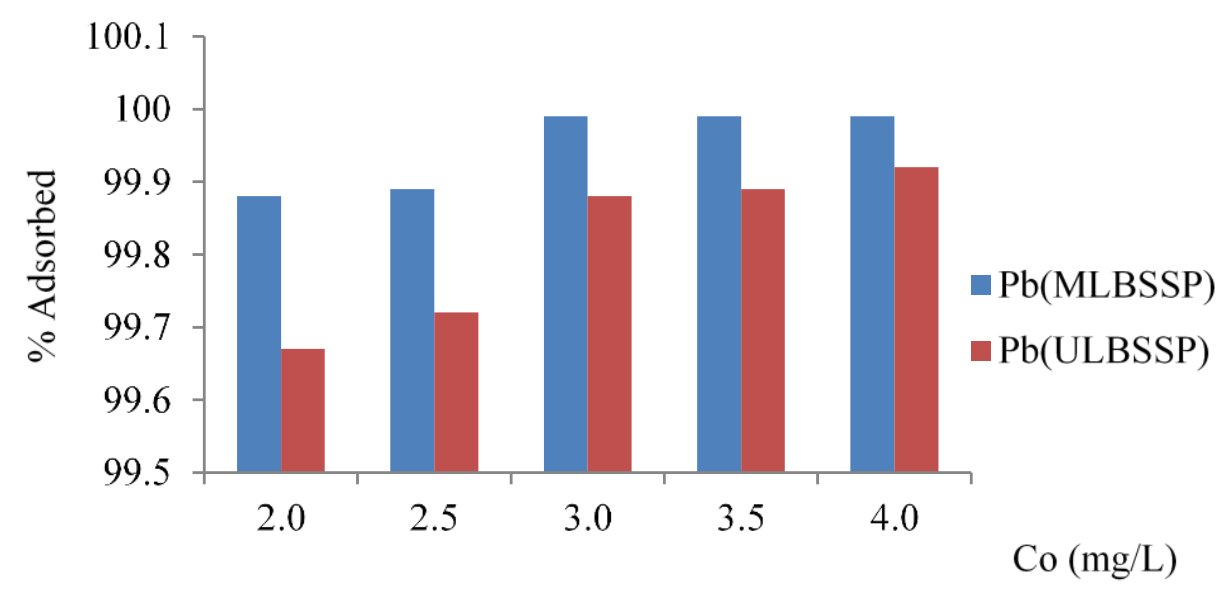

Figure 7. Effect of concentration on percent removal of $\mathrm{Pb}$ (II) ions.

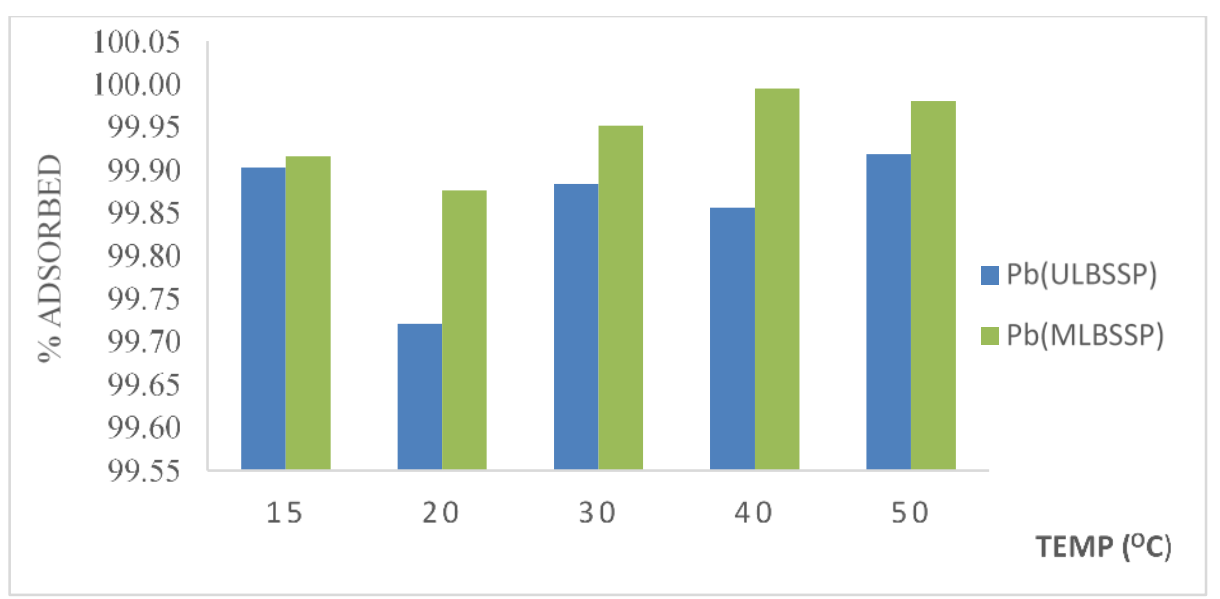

Figure 8. Effect of temperature on percent removal of $\mathrm{Pb}$ (II) ions.

time of 30 minutes indicating a dynamic equilibrium. The decrease in percentage removal at 35 minutes could be as a result of acute accumulation of ions at the surface of the adsorbent which prevent further adsorption as a result of the effect of saturation of the surface-active sites.

\section{Effect of Initial concentration}

Figure 7 show the effect of concentration on the adsorption of lead (II) ions from aqueous solutions. The graph shows that as the concentration increases the adsorption of ions increases in MLBSSP up to $2.5 \mathrm{mg} / \mathrm{L}$ of which after no visible or significant adsorption occurred. That is, with further increase in the concentration from 3.0 to $4.0 \mathrm{mg} / \mathrm{L}$, the percentage of lead (II) ions removal remain constant, indicating that a dynamic equilibrium has been attained with all the adsorption active sites been saturated which prevent further adsorption of ions onto the surface of the adsorbent. The percentage removal of ions by ULBSSP increases as the concentration increases, though with little margin but the MLBSSP showed better efficiency in lead (II) ions removal from aqueous solutions.

\section{Effect of temperature}

The study was carried out at various temperatures ranging from 15 to $50^{\circ} \mathrm{C}$ at $50 \mathrm{mg} / \mathrm{L}$ and $2 \mathrm{~g}$ adsorbent. The result of the study was presented in Figure 8. The result shows that removal efficiency was most effective with lead ions in all the adsorption temperatures in MLBSSP than ULBSSP as a result of high surface area, surface acidity, and greater availability of exchangeable sites, increase pore volume and size.

\section{Isotherm studies}

The adsorption isotherms (Langmuir and Freundlich) for 
Table 2. Langmuir isotherm constants.

\begin{tabular}{lcccccc}
\hline \multirow{2}{*}{ Metal ions } & \multicolumn{3}{c}{ ULBSCP } & \multicolumn{3}{c}{ MLBSCP } \\
\cline { 2 - 7 } & $\mathbf{Q}_{\max }(\mathbf{m g} / \mathbf{g})$ & $\mathbf{b}(\mathbf{L} / \mathbf{m g})$ & $\mathbf{R}^{2}$ & $\mathbf{Q}_{\max }(\mathbf{m g} / \mathbf{g})$ & $\mathbf{b}(\mathbf{L} / \mathbf{m g})$ & $\mathbf{R}^{\mathbf{2}}$ \\
\hline $\mathrm{Pb}^{2+}$ & -48.781 & -1.029 & 0.9172 & -1666.200 & -3.333 & 0.9476 \\
\hline
\end{tabular}

Table 3. Freundlich isotherm constants.

\begin{tabular}{lcccccc}
\hline \multirow{2}{*}{ Metal ions } & \multicolumn{3}{c}{ ULBSCP } & \multicolumn{3}{c}{ MLBSCP } \\
\cline { 2 - 7 } & $\mathbf{K}_{\boldsymbol{f}}(\mathbf{m g} / \mathbf{g})$ & $\mathbf{n}$ & $\mathbf{R}^{\mathbf{2}}$ & $\mathbf{K}_{\mathbf{f}}(\mathbf{m g} / \mathbf{g})$ & $\mathbf{n}$ & $\mathbf{R}^{\mathbf{2}}$ \\
\hline $\mathrm{Pb}^{2+}$ & -0.899 & -8.518 & 0.972 & -0.916 & -8.525 & 0.9738 \\
\hline
\end{tabular}
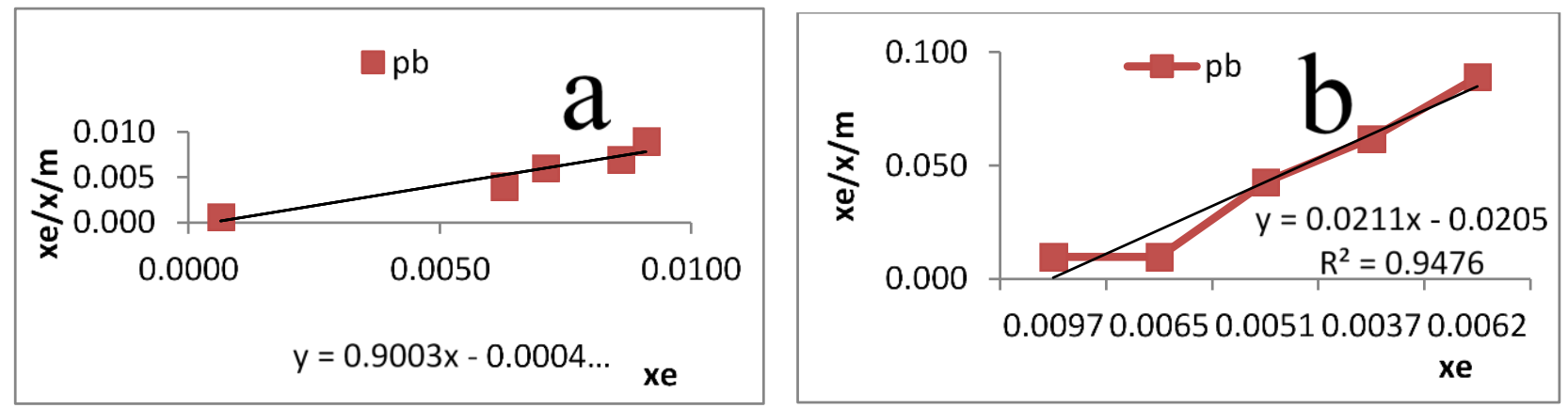

Figure 9. Langmuir isotherm for the adsorption of lead ions using powdered (a) ULBSS (b) MLBSS.
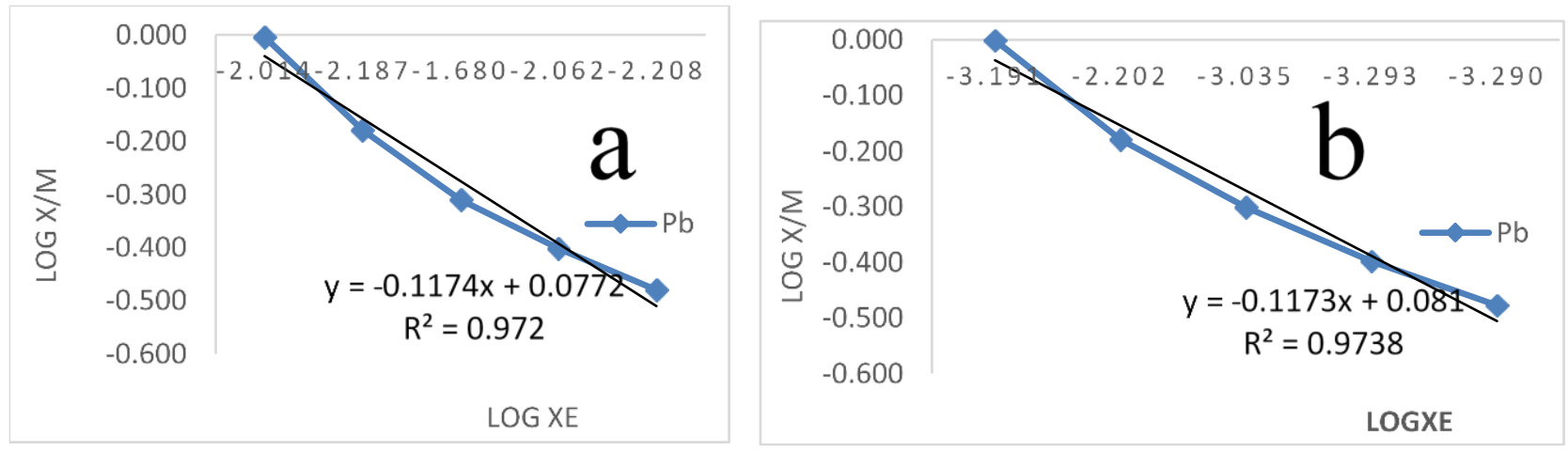

Figure 10. Freundlich isotherms for the adsorption of lead ions using powdered (a) ULBSS (b) MLBSS.

lead (II) ions were obtained for ULBSSP and MLBSSP. The corresponding adsorption parameters were summarized in Tables 2 and 3 , and the graphs were represented by Figure 9 and 10 respectively. The negative Langmuir isotherm separation factor $R_{L}$ resulting from the model calculations showed that this model is not adequate to explain this adsorption process. The results also showed that the values of $1 / n$ calculated are below one (1) for ULBSSP and MLBSSP indicating that the adsorption of the metal ions on ULBSSP and MLBSSP was favourable. However, Freundlich model was more appropriate and conformed to explain the nature of the adsorption process in both ULBSSP and MLBSSP with correlation coefficients of 0.9720 and 0.9738 compare with Langmuir correlation coefficient $\left(R^{2}\right)$ values ranging from 0.9172 to 0.9476 in ULBSSP and MLBSSP.

\section{Kinetics studies}

The correlation coefficient $\left(R^{2}\right)$ values obtained for the adsorption of lead (II) ions onto ULBSSP and MLBSSP were presented in Tables 4 and 5 and the corresponding graphs were shown in Figures 11 and 12 respectively. 
Table 4. Pseudo first order kinetic parameters.

\begin{tabular}{|c|c|c|c|c|c|c|}
\hline \multirow{2}{*}{ Metal ions } & \multicolumn{3}{|c|}{ ULBSCP } & \multicolumn{3}{|c|}{ MLBSCP } \\
\hline & $\mathrm{K}_{\mathbf{1} / \mathrm{min}}$ & $q_{e}(\mathrm{mglg})$ & $\mathbf{R}^{2}$ & $\mathrm{~K}_{1 / \mathrm{min}}$ & $q_{e}(\mathrm{mglg})$ & $\mathbf{R}^{2}$ \\
\hline $\mathrm{Pb}^{2+}$ & 0.233 & 0.004 & 0.865 & -0.231 & -1.574 & 0.942 \\
\hline
\end{tabular}

Table 5. Pseudo second kinetic parameters.

\begin{tabular}{lcccccc}
\hline \multirow{2}{*}{ Metal ions } & \multicolumn{3}{c}{ ULBSCP } & \multicolumn{3}{c}{ MLBSCP } \\
\cline { 2 - 7 } & $\mathbf{K}_{2 \mathbf{g} /(\mathbf{m g m i n})}$ & $\mathbf{q}_{2} \mathbf{m g} / \mathbf{g}$ & $\mathbf{R}^{\mathbf{2}}$ & $\mathbf{K}_{\mathbf{2 g} /(\mathbf{m g} \text { in) }}$ & $\mathbf{q} \mathbf{2} \mathbf{m g} / \mathbf{g}$ & $\mathbf{R}^{\mathbf{2}}$ \\
\hline $\mathrm{Pb}^{2+}$ & 4.068 & 0.626 & 0.9568 & 0.124 & 2.008 & 0.9662 \\
\hline
\end{tabular}
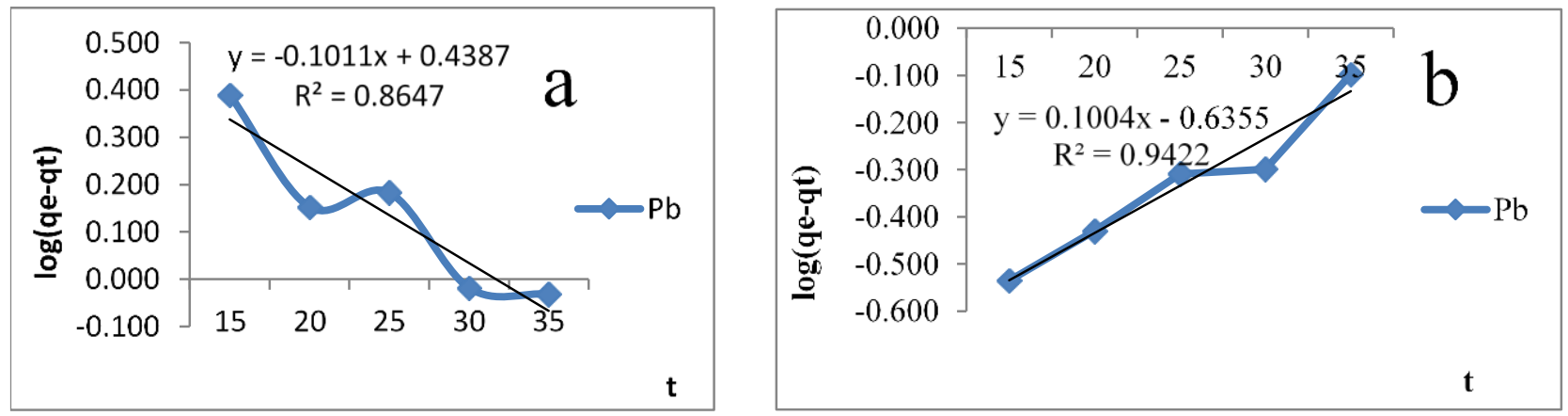

Figure 11. Pseudo-first -order for the adsorption of lead ions using powdered (a) ULBSS and (b) MLBSS.
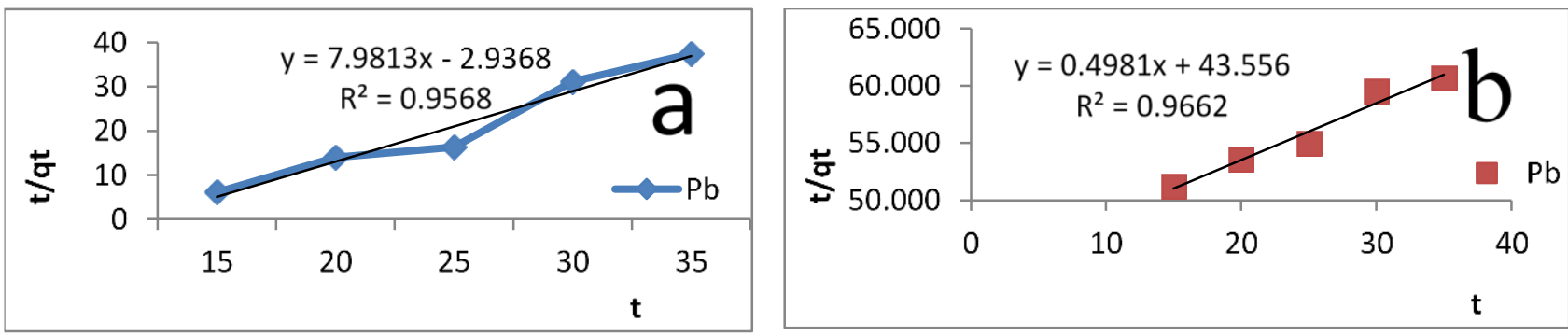

Figure 12. Pseudo-second -order for the adsorption of lead ions using powdered (a) ULBSS and (b) MLBSS.

The results showed that the $R^{2}$ of ULBSSP and MLBSSP removal of lead (II) ions were 0.865 and 0.942 respectively in pseudo-first- order kinetics. However, the values of $\mathrm{R}^{2}$ obtained in pseudo-second-order kinetic for the adsorption of lead (II) ions onto ULBSSP and MLBSSP were 0.9568 and 0.9662 respectively. Based on the values of correlation coefficient obtained pseudo-second-order kinetic model was more suitable to describe the adsorption process better than pseudo-first order model.

\section{Thermodynamics studies}

Positive values obtained for enthalpy change $(\Delta \mathrm{H})$ revealed endothermic nature of the adsorption process. The values obtained for change in entropy $(\Delta S)$ were negative suggesting that there was a decrease in the randomness between the adsorbent aqueous solutions interface during the adsorption process (Table 6).

It also showed that the degree of freedom of translational, rotational and vibrational at the transition state compared to the bulk became negligible and ineffective which is characteristic of physic-sorption and usually favoured at low temperature indicating less affinity of the adsorbent materials and less ordered adsorbed species on the surface. The free energy change for the adsorption is presented in Table 7 .

The positive free energy values at all temperatures 
Table 6. Thermodynamic parameters of the adsorption of lead ions from aqueous solutions.

\begin{tabular}{lcccc}
\hline \multirow{2}{*}{ Metal ions } & \multicolumn{2}{c}{ ULSBCP } & \multicolumn{2}{c}{ MLBSCP } \\
\cline { 2 - 5 } & $\Delta \mathbf{H}(\mathbf{k J} / \mathrm{mol})$ & $\Delta \mathbf{S}(\mathbf{k J} / \mathrm{mol})$ & $\Delta \mathbf{H}(\mathbf{k J} / \mathrm{mol})$ & $\Delta \mathbf{S ~ ( k J / m o l )}$ \\
\hline $\mathrm{Pb}^{2+}$ & 42.82 & -0.192 & 63.49 & -0.278 \\
\hline
\end{tabular}

Table 7. Values of free energy $(\Delta G)$ for the adsorption of lead ions from aqueous solutions.

\begin{tabular}{lcc}
\hline \multirow{2}{*}{ Temp(K) } & ULBSCP $\mathbf{~ J / m o l}$ & MLBSCP $\mathbf{~ J} / \mathbf{m o l}$ \\
\cline { 2 - 3 } & $\mathbf{P b}^{2+}$ & $\mathbf{P b}^{2+}$ \\
\hline 288 & 98.21 & 143.61 \\
293 & 99.17 & 145.01 \\
303 & 101.09 & 147.79 \\
313 & 103.02 & 150.57 \\
323 & 104.94 & 153.35 \\
\hline
\end{tabular}

suggested that sorption reactions were non-spontaneous and required some external energy whether inherent or induced.

\section{Conclusion}

The investigation of the potential of MLBSSP in heavy metal removal showed that it is an excellent adsorbent for heavy metals ions removal from aqueous solution. The results indicated the efficiency of MLBSSP as a good adsorbent. The adsorbent removed more than $99 \%$ using $1.0 \mathrm{~g}$ of the adsorbent dosage. The adsorption process conformed well to Freundlich isotherm and pseudo second order kinetics. The thermodynamics parameter changes in enthalpy and change in Gibb's free energy were positive indicating endothermic process and non-spontaneity of the process respectively while change in entropy values were negative suggesting decrease in the entropy of the adsorption process. MLBSSP has the potential as an adsorbent for the removal of $\mathrm{Pb}$ (II) ions from aqueous solutions. Locust bean seed shell is very cheap, readily available and environment friendly and using a simple and cost-effective modification process. It will serve as an alternative adsorbent to the expensive available adsorbents for the removal of heavy metal ions from aqueous solution and by extension from industrial effluents contaminated with traces of heavy metals.

\section{CONFLICT OF INTEREST}

The authors declare that they have no conflict of interest.

\section{REFERENCES}

Abdel-Ghani, N. T., Hefny, M., \& El-Chaghaby, G. A. (2007).
Removal of lead from aqueous solution using low cost abundantly available adsorbents. International Journal of Environmental Science \& Technology, 4(1), 67-73.

Abia, A. A., Horsfall Jr, M., \& Didi, O. (2003). The use of chemically modified and unmodified cassava waste for the removal of $\mathrm{Cd}, \mathrm{Cu}$ and $\mathrm{Zn}$ ions from aqueous solution. Bioresource Technology, 90(3), 345-348.

Achife, E. C., \& Ibemesi, J. A. (1989). Applicability of the

Ali, I., Alothman, Z. A., \& Al-Warthan, A. (2016). Sorption, kinetics and thermodynamics studies of atrazine herbicide removal from water using iron nano-composite material. International Journal of Environmental Science and Technology, 13(2), 733742.

Ariffin, N., Abdullah, M. M. A. B., Zainol, M. R. R. M. A., Murshed, M. F., Faris, M. A., \& Bayuaji, R. (2017). Review on adsorption of heavy metal in wastewater by using geopolymer. In MATEC Web of Conferences (Vol. 97, p. 01023). EDP Sciences.

Breen, C., Madejová, J., \& Komadel, P. (1995). Characterisation of moderately acid-treated, size-fractionated montmorillonites using IR and MAS NMR spectroscopy and thermal analysis. Journal of Materials Chemistry, 5(3), 469-474.

Das, B., Mondal, N. K., Bhaumik, R., \& Roy, P. (2014). Insight into adsorption equilibrium, kinetics and thermodynamics of lead onto alluvial soil. International Journal of Environmental Science and Technology, 11(4), 1101-1114.

Drake, L. R., Lin, S., Rayson, G. D., \& Jackson, P. J. (1995). Chemical modification and metal binding studies of Datura innoxia. Environmental Science \& Technology, 30(1), 110114.

Freundlich and Langmuir adsorption isotherms in the bleaching of rubber and melon seed oils. Journal of the American Oil Chemists' Society, 66(2), 247-252.

Gnanasundaram, N., Loganathan, M., \& Singh, A. (2017). Optimization and performance parameters for adsorption of Cr6+ by microwave assisted carbon from Sterculia foetida shells. In IOP Conference Series: Materials Science and Engineering (Vol. 206, No. 1, p. 012065). IOP Publishing.

Hameed, B. H., Ahmad, A. L., \& Latiff, K. N. A. (2007). Adsorption of basic dye (methylene blue) onto activated carbon prepared from rattan sawdust. Dyes and pigments, 75(1), 143-149.

Hashem, M. A., Nur-A-Tomal, M. S., Abedin, M. J., \& Bushra, S. 
A. (2017). Heavy metal assessment of polluted soil around Hatirjheel Lake of Dhaka city, Bangladesh. Bangladesh Journal of Scientific and Industrial Research, 52(1), 61-66.

Horsfall Jnr, M., \& Spiff, A. I. (2004). Studies on the effect of pH on the sorption of $\mathrm{Pb} 2+$ and $\mathrm{Cd} 2+$ ions from aqueous solutions by Caladium bicolor (Wild Cocoyam) biomass. Electronic Journal of Biotechnology 7(3), 310-320.

Horsfall Jnr, M., \& Spiff, A. I. (2005). Effects of temperature on the sorption of $\mathrm{Pb} 2+$ and $\mathrm{Cd} 2+$ from aqueous solution by Caladium bicolor (Wild Cocoyam) biomass. Electronic Journal of Biotechnology, 8(2), 162-169.

Igwe, J. C., \& Abia, A. A. (2003). Maize Cob and Husk as adsorbents for removal of cadmium, lead and zinc ions from waste water. Physical Science, 2(8),83-94.

Ketcha, J. M., Dina, D. J. D., Ngomo, H. M., \& Ndi, N. J. (2012). Preparation and characterization of activated carbons obtained from maize cobs by zinc chloride activation. American Chemical Science Journal, 2(4), 136-160.

Kouotou, D., Ngomo Manga, H., Baçaoui, A., Yaacoubi, A., \& Ketcha Mbadcam, J. (2013). Physicochemical activation of oil palm shells using response surface methodology: Optimization of activated carbons preparation. International Journal of Current Research, 5(3), 431-438.

Mittal, A. (2006). Removal of the dye, Amaranth from waste water using hen feathers as potential adsorbent. Electron. J. Environ. Agric. Food Chem., 5(2), 1296-1305.

Mondal, M. K. (2009). Removal of Pb (II) ions from aqueous solution using activated tea waste: Adsorption on a fixed-bed column. Journal of environmental management, 90(11), 32663271.

Mondal, M. K., Mishra, G., \& Kumar, P. (2015). Adsorption of Cadmium (II) and Chromium (VI) from aqueous solution by waste marigold flowers. Journal of Sustainable Development of Energy, Water and Environment Systems, 3(4), 405-415.

Ndi Nsami, J., \& Ketcha Mbadcam, J. (2013). The adsorption efficiency of chemically prepared activated carbon from cola nut shells by on methylene blue. Journal of Chemistry, 7p.

Okieimen, C. O., \& Okieimen, F. E. (2001). Enhanced metal sorption by groundnut (Arachis hypugea) Husks Modified with thioglycolic Acid. Bulletin of Pure and Applied Sciences, 20c(1), 13-20.
Parvathi, K., Nagendran, R., \& Nareshkumar, R. (2007). Lead biosorption onto waste beer yeast by-product: a means to decontaminate effluent generated from battery manufacturing industry. Electronic Journal of Biotechnology, 10(1), 92-105.

Pegnanelli, F, Mainelli, S. Veglio, F. L., Toro, L (2003). Heavy metal removal by olive pomace: Bisorbent Charactization and Equilibrium Modeling. Chemical Engineering Science, 58, 4709-4717.

Priyanka, K (2017). Effective adsorption of Cadmium (II) Ion on orange peels (Citrus sinensis). International Research Rournal of Engineering and Technology (IRJET), 4(6), 1407-1409.

Teker, M., Imamoglo, M., \& Saltabas, Ö. (1999). Adsorption of copper and cadmium lons by activated carbon from rice hulls. Turkish Journal of Chemistry, 23(2), 185-192.

Sharma, P. K., Ayub, S., \& Tripathi, C. N. (2016). Isotherms describing physical adsorption of $\mathrm{Cr}(\mathrm{VI})$ from aqueous solution using various agricultural wastes as adsorbents. Cogent Engineering, 3(1), 1186857.

Vinod, V. P., \& Anirudhan, T. S. (2002). Sorption of tannic acid on zirconium pillared clay. Journal of Chemical Technology \& Biotechnology: International Research in Process, Environmental \& Clean Technology, 77(1), 92-101.

Wu, F. C., Tseng, R. L., \& Juang, R. S. (2005). Preparation of highly microporous carbons from fir wood by $\mathrm{KOH}$ activation for adsorption of dyes and phenols from water. Separation and Purification Technology, 47(1-2), 10-19.

Zupanc, C., Hornung, A., Hinrichsen, O., \& Muhler, M. (2002). The interaction of hydrogen with $\mathrm{Ru} / \mathrm{MgO}$ catalysts. Journal of Catalysis, 209(2), 501-514. 